\title{
RECORRIDO POR LAS ACCIONES DE LAS ORGANIZACIONES CIVILES DE DERECHOS HUMANOS EN AMÉRICA LATINA
}

\author{
Erli Margarita Marin Aranguren ${ }^{(a)}$ \\ Daniela González Jaramilloçc(b)
}

\author{
REVIEWING THE ACTIONS OF CIVIL HUMAN RIGHTS \\ ORGANIZATIONS IN LATIN AMERICA \\ PERCURSO PELAS AÇÕES DAS ORGANIZAÇÕES CIVIS \\ DE DIREITOS HUMANOS EM AMÉRICA LATINA
}

Fecha de recepción: 23 de septiembre del 2019

Fecha de aprobación: 12 de diciembre del 2019

Disponible en línea: 31 de diciembre del 2019

\section{Sugerencia de citación:}

Marín-Arangureny, E. M. y González Jaramillo, D. (2020). Recorrido por las acciones de las organizaciones civiles de derechos humanos en América Latina. Razón Crítica, 8, 21-53, doi: $10.21789 / 25007807.1571$

(1) El presente artículo hace parte del proyecto de investigación "La Sociedad Civil Global en el abordaje de algunos de sus temas inherentes a comienzos del siglo XXI" del Observatorio de Análisis de los Sistemas Internacionales -OASIS- de la Universidad Externado de Colombia. Este proyecto está dirigido por la docente Erlí Margarita Marín-Aranguren.

(a) Erli Margarita Marín-Aranguren

Profesora titular e investigadora CIPE - Facultad de Finanzas, Gobierno y Relaciones Internacionales, Universidad Externado de Colombia, Colombia.

erli.marin@uexternado.edu.co

https://orcid.org/0000-0002-1779-7138

(b) Daniela González Jaramillo

Profesional en Finanzas y Relaciones Internacionales Facultad de Finanzas, Gobierno y Relaciones Internacionales, Universidad Externado de Colombia, Colombia. daniela.gonzalezj7@gmail.com https://orcid.org/0000-0002-1713-4553 


\section{R E S U M E N}

Durante el siglo XXI, la sociedad civil ha tenido un rol fundamental en la lucha por la garantía de los Derechos Humanos (DDHH). Este escrito se enfoca en describir y analizar el accionar de las Organizaciones de la Sociedad Civil (OSC) en pro de garantizar la protección de los DDHH. El eje del análisis estuvo en América Latina, a través del estudio de variables como: seguridad alimentaria, erradicación de la pobreza y la desigualdad, lucha por los derechos de las mujeres y erradicación de la violencia. Este análisis permite visibilizar el aporte de las OSC latinoamericanas a la población vulnerable en la región.

PALABRAS CLAVE: Human rights, Protection, Civil society Organizations, Implementation, Actions. 


\section{A B S T R A C T}

During the 21st century, civil society has played a key role in enforcing human rights (HR). This paper focuses on the actions of the Latin American Civil Society Organizations (CSOs) in guaranteeing the protection of HR. Specifically, the paper analyses the following variables: food safety, poverty and inequality eradication, defense of women's rights and violence eradication. We aim to make visible the contribution that Latin American CSOs have provided through their actions to vulnerable people.

KEYWORDS: Human rights, Protection, Civil society

Organizations, Implementation, Actions.

\section{R E S U M O}

No século XXI, a sociedade civil tem desempenhado um papel fundamental na luta pela garantia dos Direitos Humanos (DDHH).

Este escrito foca-se na descrição e análise do agir das Organizações da Sociedade Civil (OSC) na procura de garantir a proteção dos DDHH. O eixo central de análise foi a América Latina, através do estudo de variáveis como: segurança alimentar, erradicação da pobreza e a desigualdade, luta pelos direitos das mulheres e erradicação da violência. Esta análise permite visibilizar o aporte das OSC da América Latina à população vulnerável na região.

PALAVRAS-CHAVE: Direitos Humanos, Proteção, Organizações da Sociedade Civil, Implementação, Ações. 


\section{N T R O D U C C I Ó N}

América Latina se ha caracterizado por su diversidad étnica y cultural, su variedad de sabores y colores, su riqueza en recursos naturales, tierras cultivables, yacimientos de petróleo y gas. Sin embargo, aun cuando su diversa riqueza la convierte en una región excepcional, la fragilidad política, económica y social que ha caracterizado a esta parte del continente, la ha llevado a periodos de turbulencia e inestabilidad. De ahí surge la preocupación por proteger y defender los derechos humanos (DDHH). Desde mediados del siglo XX, crímenes de lesa humanidad cometidos en varios países de la región motivaron el surgimiento de movimientos sociales y organizaciones de la sociedad civil (OSC) en la búsqueda de la protección de los ciudadanos y ciudadanas ante los brotes de violencia que caracterizan el devenir de la región.

Quien haga una ligera revisión a la ratificación de los tratados para la protección de los DDHH, puede advertir que este asunto está en la agenda de la región desde hace varias décadas. De los 17 tratados para la protección de los DDHH, que para 2017 se consideraban los más relevantes $^{1}, 12$ estaban ratificados por 20 de los 42 países de América Latina y el Caribe (ALC) (CIDH y OEA, 2017), siendo Argentina, Uruguay, Bolivia, República Dominicana, Perú, Brasil y Colombia los países que más se han comprometido con los marcos jurídico-políticos del orden internacional.

1 Sean suscritos en la Organización de las Naciones Unidas (ONU) o en la Organización de Estados Americanos (OEA). 
Sorprende que, si bien la región ha desempeñado un rol protagónico en la defensa de los DDHH, de los 281 homicidios contra defensores de DDHH registrados a nivel global en 2016, en la región ocurrieron 217 (INDEPAZ, IEPRI, CINEP/PPP y CCJ, 2017, p. 7). También llama la atención que el 90\% de ellos sigue impune (Amnistía Internacional, 2018). El hecho es que, en la región, se asesina diariamente a 12 mujeres (Cadena, 2015), por motivo de género. Con el $8 \%$ de la población mundial, América Latina y el Caribe concentra 33\% de los homicidios mundiales. Esto es, una tasa de 21,5 homicidios por cada 100.000 habitantes (INDEPAZ, IEPRI, CINEP/PPP y CCJ, 2017). Más de tres veces el promedio global que es de 7 asesinatos por cada 100.000 habitantes (Agencia Anadolu, 2018).

Cuando se hace referencia a la protección de derechos no solo se trata de los asesinatos, también ha de contemplarse: la inseguridad alimentaria o nula soberanía para poder alimentarse, la situación de pobreza y desigualdad, los derechos de las mujeres y la erradicación de la violencia. Derechos de segunda generación que deben respetarse tanto como los de primera generación.

Entonces, es inpensable para la región que más de 32 millones de personas vivan bajo condiciones de inseguridad alimentaria y que el 30,7\% de su población total sea pobre (FAO, 2017). Los informes de OXFAM y CEPAL permiten advertir que en ALC la distribución de la tierra es la más desigual del planeta. Basta saber que un multimillonario gana 1.154 veces más que una persona pobre y que, el coeficiente de Gini, aplicado a la distribución de la tierra, es del 0,79 (superando el registro en Europa de 0,57 , África de 0,56 y Asia de 0,55). Todo ello sucede en el 13,5\% de la superficie emergida del planeta, es decir, en un poco más de veinte millones de kilómetros cuadrados de superficie terrestre (OXFAM, 2016).

En la región se han ratificado el 70,59\% de los tratados de DDHH, sin embargo, lo que se advierte es que los estados de ALC son "ratificadores" ejemplares y deberían ser los actores protagónicos. No obstante, la protección real de los DDHH dista mucho de aquel ejemplo. Basta mirar las condiciones internas y coyunturales de cada país. Por esto resulta relevante analizar el rol de las OSC que comparten la misma búsqueda de justicia, igualdad y respeto a la dignidad humana.

Por ello, es imprescindible preguntarse por su accionar en la región. En este sentido, la principal pregunta que mueve este artículo es: ¿Qué acciones emprendieron las OSC para la protección de los DDHH en América Latina y el Caribe, en lo corrido del siglo XXI? El objetivo es identificar las acciones que las OSC de ALC realizaron, entre 2000 y 2018, 
en cuatro frentes: seguridad alimentaria, erradicación de la pobreza y la desigualdad, lucha por los derechos de las mujeres y erradicación de la violencia. Se parte de la hipótesis de que las OSC de ALC han estado articuladas para superar el menosprecio a la dignidad humana, y siempre lo han hecho dentro del marco legal porque han comentado lo que sucede en la región, han meditado las implicaciones y han negociado sobre las acciones urgentes para proteger y garantizar los DDHH.

\section{METODOLOGÍA DEL TRABAJO INVESTIGATIVO}

La investigación que se adelantó fue de tipo cualitativo-descriptivo. En primera instancia, se hizo una revisión documental de 100 OSC y OIG, basado en la jurisprudencia y normativa (consideradas fuentes primarias), y en los documentos disponibles en internet de las organizaciones intergubernamentales, las entidades públicas y las organizaciones de la sociedad civil involucradas (consideradas fuentes secundarias), para encontrar el nivel de compromiso de los países latinoamericanos en la promoción de los DDHH.

En segunda instancia, se hizo un barrido en internet del accionar de las OSC, cuando estas trabajan los temas de DDHH. Para ello se construyó una base de datos a partir de la revisión electrónica de medios de comunicación (El Tiempo, El Espectador, Contagio Radio, El País, BBC Mundo). De este modo fueron seleccionadas 20 OSC que representan la base de este estudio: Acción contra el Hambre, Hambre Cero, ABACO, ACODRES, Feeding America, AIESEC, Oxfam Intermón, Acción Ciudadana, Fundación Superación de la Pobreza, Manos Unidas, Casa del Encuentro, Colectivo Mujeres de Negro, Paro Internacional de Mujeres, ELA, FEIM, Amnistía Internacional, Asocia 2030, Front Line Defenders, CCONG y Think Tank Civismo. Estas 20 OSC fueron clasificadas en cuatro variables o matrices: seguridad alimentaria, erradicación de la pobreza y la desigualdad, lucha por los derechos de las mujeres y erradicación de la violencia. De esta manera se procedió a profundizar en sus portales web y en sus redes sociales (Facebook, Instagram y Twitter), buscando las consignas/lemas de las campañas más relevantes.

Luego, en tercera instancia, para cada variable, se tuvo en cuenta el modelo que acogió el Banco Mundial, sobre las funciones básicas de las OSC. La matriz fue diligenciada con la información de 5 organizaciones 
activas en cada función. Estas organizaciones fueron seleccionadas de manera aleatoria, según el accionar y su registro en internet.

Finalmente, en cuarta instancia, se exaltan las acciones específicas de las organizaciones analizadas en cada una de las variables, siguiendo el modelo del Banco Mundial. Así se determina no solo la acción precisa de éstas en cada función sino cómo están concatenadas para meditar, comentar y negociar en lo referente a la protección y garantía de DDHH.

De este modo, a partir de los referentes teórico-conceptuales de las funciones que desempeñan las OSC, el lector encontrará algunas pautas para acercarse al agente y el tema. Posteriormente, se realizará una contextualización de la vulneración de derechos en la región, así como una explicación del trabajo realizado por los entes gubernamentales a nivel global para su protección, a partir de las cuatro variables de análisis (seguridad alimentaria, erradicación de la pobreza y la desigualdad, lucha por los derechos de las mujeres y erradicación de la violencia). Estas variables corresponden a la segunda generación de derechos humanos en los que las OSC han tenido un mayor rol.

Finalmente, se identifican las acciones colectivas desplegadas por las OSC en Latinoamérica (campañas, movimientos, peticiones, conciertos, brigadas de alimentación, participación en la creación de políticas públicas, creación e implementación de leyes), para de esta manera, presentar conclusiones generales sobre el accionar de las OSC en la región.

\section{Algunas pautas para acercarse al agente y al tema desde una visión teórica}

Los dos referentes centrales son: sociedad civil y pobreza. Con respecto al primero, hay que denotar la polisemia que ha representado a lo largo de la historia, luego se retoman las funciones o los roles que establecen los académicos. Así, se expone que el concepto de sociedad civil ganó importancia en América Latina, especialmente en la lucha contra las dictaduras militares de mediados del siglo pasado. Desde ese momento, el término se ha extendido para hacer frente a un rango de actividades, que va desde modelos antiautoritarios hasta la libertad económica (incluyendo la lucha por la desregulación) (Paffenholz y Spurk, 2006). Lo cierto es que este término es ampliamente usado, pero complejo de acotar.

Existen gran variedad de definiciones que agrupan diferentes funciones de las organizaciones que la conforman, dependiendo del contexto espacial y temporal. En términos generales, la sociedad civil es el sector de la acción voluntaria a través de las formas institucionales, 
distintas e independientes del Estado, la familia y el mercado, pero no indiferente frente a ellos. Su accionar está orientado hacia la consecución de intereses específicos e interactúa constantemente en la esfera pública. Está compuesta por actores no estatales, y asociaciones que no están dirigidas puramente por intereses privados o económicos (Paffenholz \& Spurk, 2006, p. 5). Es importante aclarar que la existencia de las OSC es fundamental para la construcción de capital social.

En una definición descriptora se pueden identificar como sus componentes: grupos religiosos, sector solidario (en Colombia lo integran los fondos, las cooperativas y las mutuales), gremios, clubes, clanes, fundaciones (empresariales, familiares, independientes), think tanks o centros de pensamiento (el sector académico excluyendo el público), Organizaciones No Gubernamentales (ONG) (de medio ambiente, de DDHH y de desarrollo), organizaciones filantrópicas, asociaciones de profesionales y corporaciones. En fin, esa gama que, desde la norma jurídica, se conoce como Entidades Sin Ánimo de Lucro (ESAL). Quizás las características más relevantes que los lectores han de tener presentes para identificar a dichos agentes es que son heterogéneos, siempre trabajan con sentido altruista, se autogobiernan y pueden tener alcances, locales, nacionales, regionales o globales.

Los académicos establecen diferentes roles o funciones para las OSC. Aquí se retoman las propuestas de tres modelos que han tenido acogida en el Banco Mundial: Merkel and Lauth's Function Model, Edward's Role Model y Paffenholz y Spurk's Cooperation Model (Paffenholz \& Spurk, 2006) $)^{2}$. A partir de estos modelos, se tomaron siete funciones puntuales de las OSC para los temas de protección de derechos y su respectivo accionar (Ver tabla 1).

Es preciso anotar que las funciones enunciadas anteriormente no son secuenciales, lo que quiere decir que hay organizaciones que se focalizan en una o un par, pero pocas tienen la robustez para gestionarlas todas. Lo que se puede advertir es que, las OSC son entendidas como portadoras de valores. Con sus acciones apoyan la reconstrucción de la sociedad a través de tres aspectos

2 Autores como Merkel \& Lauth presentaron un modelo de cinco funciones que desempeña la sociedad civil en diferentes contextos y condiciones sociales, asumiendo a la OSC como una categoría de análisis. Por su parte, Paffenholz \& Spurk retoman el trabajo realizado por Merkel \& Lauth, y establecen que las funciones no son exclusivas de las OSC. También reconocen "el deber ser del Estado, como el actor que debe proveer protección y seguridad, a través de autoridades policiales y del poder judicial” (Paffenholz \& Spurk, 2006). 
principales: un cambio en los hábitos de sus integrantes, evitando la revictimización de los ciudadanos y tratando las violaciones a los DDHH desde las posibles causas (intolerancia), hasta las soluciones integradoras (cooperación).

Tabla 1. Funciones básicas de las OSC en la protección de los DDHH

\begin{tabular}{|c|c|c|}
\hline 1 & Funciones & Acciones \\
\hline 2 & Protección & $\begin{array}{c}\text { Defender, denunciar violaciones, reunirse o manifestar } \\
\text { pacíficamente, exigir fin de la vulneración de DDHH, } \\
\text { reclamar instrumentos jurídicos que protejan a la ciudadanía. }\end{array}$ \\
\hline 3 & Monitoreo & $\begin{array}{r}\text { Controlar y supervisar el cumplimiento e implementación de } \\
\text { los tratados ratificados. }\end{array}$ \\
\hline 4 & Abogacía & $\begin{array}{r}\text { Participar en la creación de agendas públicas, nacionales } \\
\text { e internacionales: debatiendo y promoviendo ideas en } \\
\text { representación de los ciudadanos frente al Estado. }\end{array}$ \\
\hline 5 & Cocialización & $\begin{array}{r}\text { Crear consciencia, implementar pedagogía y transmitir } \\
\text { valores para reintegrar y reconstruir la sociedad. }\end{array}$ \\
\hline 6 & Intermediación/Facilitación & $\begin{array}{c}\text { Fortalecimiento de vínculos entre ciudadanos, construir } \\
\text { capital social entre grupos mediante el diálogo con los } \\
\text { actores sobre los DDHH. }\end{array}$ \\
\hline 7 & Prestación de servicios & $\begin{array}{r}\text { Balancear el poder entre las autoridades estatales, los } \\
\text { ciudadanos y el mercado. }\end{array}$ \\
\hline
\end{tabular}

Fuente: Elaboración propia con información tomada de Paffenholz y Spurk (2006).

Para este estudio se tuvieron en cuenta los datos de informes presentados por varias OIG como: Oficina del Alto Comisionado para los Derechos Humanos (ACNUDH), Comisión Interamericana de Derechos Humanos (CIDH), Organización de los Estados Americanos (OEA), Organización de las Naciones Unidas para la Alimentación y la Agricultura (FAO), el Fondo de las Naciones Unidas para la Infancia (UNICEF), ONU MUJER, el Programa Mundial de Alimentos (PMA), Banco Interamericano de Desarrollo (BID), el Observatorio de Igualdad de Género de la CEPAL y la Organización Mundial de la Salud (OMS). Igualmente, fueron utilizados datos de entes no gubernamentales como: el Centro de Estudios Distributivos, Laborales y Sociales (CEDLAS), Amnistía Internacional (AI), Oxfam Intermón, Front Line Defenders, Asocia 2030, Acción Contra el Hambre, Hambre Cero y Casa de Encuentro. Además, como se mencionó, se trianguló la información con hallazgos en medios de comunicación (BBC Mundo, La W Radio, Contagio Radio). 
El segundo referente que requiere precisión es el de pobreza. Aquí se aborda desde una perspectiva de derechos. Definida como la situación socioeconómica que constituye incapacidad para suplir las necesidades físicas y mentales básicas para vivir una vida digna3. Esto "ocasiona un problema traducido en obstáculos para el goce y ejercicio de los derechos humanos en condiciones de igualdad real por parte de las personas, grupos y colectividades que viven en dicha situación” (CIDH y OEA, 2017, p. 11).

\section{LA GRISIS DE DDHH Y LA DENUNGIA DE LAS OSC EN LA REGIÓN}

En los registros de prensa se leen los reportes de informes de OIG y ONG que dan cuenta de la inseguridad, los homicidios, la desigualdad, el hambre, la discriminación de minorías, la desprotección de los derechos de las mujeres y niñas, entre otros problemas que se intensifican en unos territorios más que en otros. Como quiera que sea, estos son problemas que representan "violación a los DDHH".

Todo esto representa un contrasentido. Los estados latinoamericanos fueron protagonistas y pioneros históricos en la garantía y respeto por los DDHH, al firmar en Bogotá (1948) la Declaración Americana de los Derechos y Deberes del Hombre, que precedió a la Declaración Universal de los Derechos Humanos de las Naciones Unidas (CIDH, 2018). De hecho, esa carta se constituye en el primer tratado internacional para evitar la vulneración.

No obstante, en los 50 años posteriores a la declaración, la mayor parte de países de la región sufrió disrupciones en temas económicos, sociales y políticos, lo que generó una regresión en la protección y defensa de los DDHH. Recuérdese que, desde que la región fue colonizada, han sido constantes históricas: la violencia, la explotación económica, la desigualdad social, la discriminación contra poblaciones indígenas o minoritarias, la corrupción, el caudillismo y silenciamiento político, la represión y la desigualdad. 


\section{El hambre, una realidad latente en la región}

Los datos de la FAO, divulgados por los diferentes medios de comunicación, dan cuenta de cifras que no tienen lógica. En Bolivia 1 de cada 5 personas se encuentra en situación de hambruna $(19,8 \%$ de la población). Venezuela, en los últimos 15 años, cuadruplicó el número de personas padeciendo hambre. En Guatemala, $46 \%$ de los niños menores de 5 años presenta desnutrición crónica. En Nicaragua y Honduras el $20 \%$ de los niños vive situaciones precarias de alimentación. En Colombia, uno de cada cinco niños padece desnutrición crónica (Los 3 países con más hambre en América Latina (y el único donde aumentó en la última década). (BBC News, 2018).

Contrariamente, lo que se encuentra es que en la región se generan desperdicios del orden de las 348.000 toneladas de alimentos al día (BID, 2017), alrededor de 127 millones de toneladas al año. Es decir, se pierde alrededor del 15\% de sus alimentos disponibles. En el 2017, Argentina desperdició 16 millones de toneladas/año de alimentos. Le sigue Brasil, donde se pierden 14,6 millones de toneladas anuales, con lo que se podría alimentar a 19 millones de brasileños. Ya Colombia pierde 9,7 millones de toneladas/año, con los que se podría alimentar 8 veces a la población de La Guajira en un año (BBC News, 2017).

Como parte de los hallazgos de la evaluación sobre el accionar de las OSC en la lucha por la seguridad alimentaria en la región, se pudo determinar que las 5 OSC analizadas (Acción contra el Hambre, Hambre Cero, ABACO, ACODRES, Feeding América), cumplen la función de intermediación, mediante la Generación de Redes. De este modo promueven los lazos de cooperación para hacer frente a los retos a los cuales se enfrenta ALC en sus programas locales y nacionales de seguridad alimentaria. De igual manera, mediante la prestación de servicios, promueven las acciones de pedagogía para aproximarse a la población rural, compartir información y dialogar sobre los alcances de los programas rurales.

El fortalecimiento de dichas redes de trabajo ha dado lugar a la cohesión social con nuevos grupos de agricultores, productores y consumidores. De modo que, cuando se trata de seguridad alimentaria, las OSC "sirven de marco para debatir, planificar y ejecutar actividades de colaboración en materia de desarrollo rural y seguridad alimentaria e intensificar los esfuerzos de los gobiernos nacionales para aplicar los compromisos del Plan de Acción de la Cumbre Mundial de la Alimentación” (Noticias ONU, 2018). 
De hecho, estas OSC promueven el intercambio de ideas y de experiencias relacionadas con el campo y los ciudadanos, intensifican la participación de otras OSC para la promoción de programas rurales, facilitan el diálogo político multiactor. Además, se identificó que las 5 fomentan la creación de subredes, y en este sentido apoyan programas gubernamentales para aumentar la inversión para la agricultura y la producción de alimentos (Ver Matriz 1).

Esto es, en su accionar, las OSC estudiadas traslapan las funciones de protección, cohesión social, abogacía y prestación de servicios. Sin embargo, es notable una ausencia en la defensa y la promoción del empoderamiento ciudadano.

\section{Pobreza desde una perspectiva de derechos humanos}

En ALC muestra actualmente una tendencia al estancamiento en los esfuerzos por la reducción de la pobreza (CEPAL, 2018a). A pesar de que esta se redujo en un $15,2 \%$ en el periodo comprendido entre 20022016, las cifras indican que el número de personas (168 millones) que viven en esta situación aumentó. El reporte de la CEPAL de 2017 sitúa a 186 millones de personas (30,7\% de la población), en situación de pobreza (CEPAL, 2018b, p. 88).

En términos de desigualdad, se considera que el $90 \%$ obedece a diferencias al interior de los países. Por su parte, el $89 \%$ de los latinoamericanos considera que la distribución de los ingresos en sus respectivos países es injusta (Amarante, Galván y Mancero, 2016). Lo que se encuentra al analizar el índice de desigualdad, según el índice Gini, es que la lista la lideran Brasil $(51,3)$ y Colombia $(50,8)$, seguido de Panamá $(50,4)$ y Honduras $(50)$, manteniendo un nivel de desigualad promedio en la región de $(46,2)$ en los 20 países de ALC.

Los estudios de las ONG de desarrollo como Oxfam muestran que el $10 \%$ más rico de la región concentra el $68 \%$ de la riqueza total, mientras que el $50 \%$ más pobre accede al 3,5\%. Lo más grave es que el número de personas que padecen hambre ha aumentado por tercer año consecutivo, estableciéndose en 32,3 millones. De esta población, 11 millones están en América Central y el Caribe y 21,3 están en América del Sur (Oxfam: "El 10\% más rico de Latinoamérica concentra el 68\% de riqueza”. 2018, 22 de enero). 
Matriz 1: Evaluación del accionar de las OSC en la lucha por la seguridad alimentaria

\begin{tabular}{|c|c|c|c|c|c|c|}
\hline \multirow[b]{2}{*}{ Funciones } & \multirow[b]{2}{*}{ Acciones OSC } & \multicolumn{5}{|c|}{ OSC } \\
\hline & & $\begin{array}{l}\text { Acción } \\
\text { contra el } \\
\text { hambre }\end{array}$ & Hambre cero & Abaco & Acodres & $\begin{array}{l}\text { Feeding } \\
\text { America }\end{array}$ \\
\hline \multirow{3}{*}{ Protección } & Defender & & & & & \\
\hline & Denunciar & $\sqrt{ }$ & $\sqrt{ }$ & & & \\
\hline & Movilización & $\sqrt{ }$ & & $\sqrt{ }$ & $\sqrt{ }$ & \\
\hline \multirow{2}{*}{ Monitoreo } & Supervisar & & $\sqrt{ }$ & & $\sqrt{ }$ & $\sqrt{ }$ \\
\hline & Promover & $\sqrt{ }$ & $\sqrt{ }$ & $\checkmark$ & $\checkmark$ & $\sqrt{ }$ \\
\hline \multirow{7}{*}{ Abogacía } & $\begin{array}{l}\text { Difusión de la } \\
\text { información }\end{array}$ & $\checkmark$ & $\mu$ & $\checkmark$ & & $\checkmark$ \\
\hline & Comentar & $\sqrt{ }$ & $\mathcal{V}$ & $\checkmark$ & & $\sqrt{ }$ \\
\hline & Dialogar & $\sqrt{ }$ & & & $\sqrt{ }$ & \\
\hline & Negociar & & & & $\sqrt{ }$ & \\
\hline & $\begin{array}{c}\text { Incidencia } \\
\text { Política }\end{array}$ & & & & $\checkmark$ & \\
\hline & Sensibilizar & $\sqrt{ }$ & $\sqrt{ }$ & $\sqrt{ }$ & & $\sqrt{ }$ \\
\hline & Participar & & & $\checkmark$ & $\sqrt{ }$ & $\sqrt{ }$ \\
\hline \multirow{2}{*}{ Intermediación } & $\begin{array}{c}\text { Generación de } \\
\text { redes }\end{array}$ & & & $\checkmark$ & $\sqrt{ }$ & $\sqrt{ }$ \\
\hline & $\begin{array}{c}\text { Representación } \\
\text { ciudadanía }\end{array}$ & & & & & \\
\hline \multirow{3}{*}{$\begin{array}{c}\text { Cohesión } \\
\text { social }\end{array}$} & $\begin{array}{l}\text { Creación de } \\
\text { comunidad }\end{array}$ & $\sqrt{ }$ & $\sqrt{ }$ & & & \\
\hline & $\begin{array}{c}\text { Empoderamiento } \\
\text { ciudadano }\end{array}$ & & & & & \\
\hline & $\begin{array}{c}\text { Transmisión } \\
\text { de valores }\end{array}$ & $\checkmark$ & $\mathscr{J}$ & $\checkmark$ & & $\checkmark$ \\
\hline \multirow{4}{*}{$\begin{array}{c}\text { Prestación de } \\
\text { servicios }\end{array}$} & Socialización & $\checkmark$ & $\checkmark$ & & $\checkmark$ & $\sqrt{ }$ \\
\hline & $\begin{array}{c}\text { Trabajo en } \\
\text { comunidades }\end{array}$ & $\sqrt{ }$ & $\sqrt{ }$ & $\sqrt{ }$ & & $\sqrt{ }$ \\
\hline & $\begin{array}{l}\text { Asistencia } \\
\text { ciudadana }\end{array}$ & $\sqrt{ }$ & $\mathcal{I}$ & $\mathcal{J}$ & & $\checkmark$ \\
\hline & Pedagogía & & & $\checkmark$ & $\sqrt{ }$ & $\mathcal{V}$ \\
\hline
\end{tabular}

Fuente: Elaboración propia. 
De acuerdo con el Pacto Internacional de Derechos Económicos, Sociales y Culturales y de la Convención Americana de Derechos Humanos, los estados tienen la obligación de satisfacer los niveles esenciales de todo ser humano. El incumplimiento de estos mínimos básicos constituye una falta a las obligaciones establecidas en los tratados internacionales. La pobreza y desigualdad, no solo entendidas como un factor económico, sino como un fenómeno multidimensional que afecta las capacidades básicas para vivir, se convierten a diario en una de las causas por las cuales son desatendidas las necesidades de todo individuo y, por ende, en un grave obstáculo para el goce efectivo de los DDHH.

La intermediación de las OSC comprende la generación y articulaciones de redes como lo hacen AISEC, Oxfam Intermón, Acción Ciudadana, Fundación Superación y Manos Unidas. En realidad, las OSC desarrollan capacidades tanto técnicas como prácticas que pueden trabajar de manera armónica en el fortalecimiento institucional y la reducción de la pobreza y la desigualdad. Para ello trabajan con un enfoque de cambio, sea este individual, familiar o comunitario. Esto lo hacen, por ejemplo, AISEC, Oxfam Intermón, Acción Ciudadana y Manos Unidas. De este modo, se busca la autonomía de las personas y comunidades con el objetivo de convertirlos en agentes principales de su desarrollo. Si bien, las OSC no pueden resolver el factor económico de sus grupos focales, han trabajado en la superación del déficit alimentario, fomento del capital humano y el desarrollo de capacidades desde un enfoque de necesidades básicas.

En el desarrollo de la investigación emergen datos con los que se da cuenta de la incidencia política que desarrollan AISEC, Oxfam Intermón, Acción Ciudadana, Fundación Superación. Estas organizaciones afirmaron haber participado de manera activa en la discusión de proyectos que surtieron un efecto legislativo. Asimismo, se destacaron acciones encaminadas a la sensibilización del Estado respecto a la importancia que tiene el tema desde un enfoque de DDHH, así como la colaboración en el diseño de recomendaciones de política en este ámbito.

Cabe destacar, también, el papel que han desarrollado como difusoras de información (AISEC, Oxfam Intermón, Acción Ciudadana y Manos Unidas), para ello adelantan estudios y publicaciones resultado de seminarios, foros y encuentros, en los que se discute el tema de la garantía del derecho a la equidad y a unos mínimos básicos. Además, dichas OSC han cooperado en la difusión de experiencias que se han derivado de la implementación de sus programas, además de facilitar el acceso a información por medios impresos y virtuales. 
En términos de la función de protección, pueden destacarse actividades de defensa como las que hace Oxfam Intermón. En realidad, estas acciones están en descenso, pues las OSC coinciden en afirmar que las acciones de asistencialismo fomentan un vínculo de una sola vía, lo que impide superar la situación de emergencia. Si bien, hay actividades de trabajo con las comunidades (programas de inversión, garantía de acceso a derechos fundamentales), falta un desarrollo más amplio que proteja a la población pobre (Ver matriz 2).

\section{Los asesinatos tienen género en la región}

En América Latina no se registran enfrentamientos bélicos entre países, pero la región está marcada por la violencia interna. E1 50\% de los delitos se producen en las calles, y son cometidos por un porcentaje muy pequeño de la población (BID, 2017). Entre 2000 y 2016, más de 2,5 millones de ciudadanos fueron víctimas de homicidio. No obstante, la situación es diferenciada en cada territorio. En el caso de Argentina, Chile y Uruguay las tasas son menores a la media global, mientras que Brasil, Colombia y Venezuela acumulan la cuarta parte de los homicidios registrados en el planeta (INDEPAZ, IEPRI, CINEP/PPP Y CCJ, 2017).

Lo que se quiere destacar aquí es que los asesinatos tienen género. Para 2017, América Latina era la región del mundo con mayores índices de violencia contra la mujer, pues se registraban en promedio 12 feminicidios diarios, frente a un promedio mundial de 1 o 2 cada 30 horas. Este hallazgo emerge de las coincidencias encontradas en los informes de ONU (2018b), CEPAL (2018c) y Amnistía Internacional (2018).

Para el año 2016, en 17 países de la región (14 de América Latina y 3 del Caribe), un total de 1.998 mujeres fueron víctimas de feminicidio. Ya en 2017 este número aumenta a 2.554 víctimas (CEPAL, 2018c). Las causas, la concentración y la cantidad de estas muertes varía según el país, por lo que este tema será ampliado más adelante.

El asesinato de mujeres o niñas por razones de género es tipificado como feminicidio. "Entre los distintos tipos de feminicidio, el asesinato de la pareja y el asesinato de una mujer precedido de su violación sexual (feminicidio sexual fuera del ámbito de la pareja) son los más comunes en América Latina" (CIDH, 2010). Este es un tema crítico en la agenda mundial. En Brasil, de marzo de 2016 a marzo de 2017, fueron identificados 2.925 casos. Esto significa que cada tres horas fue asesinada una mujer en este país. En Venezuela se contabilizaron 290 asesinatos por razones de género entre 2015 y 2016 (Meléndez, 2018). En México, 
Matriz 2: Evaluación del accionar de las OSC por la erradicación de la pobreza y la desigualdad

\begin{tabular}{|c|c|c|c|c|c|c|}
\hline \multirow{2}{*}{ Funciones } & \multirow{2}{*}{ Acciones/OSC } & \multicolumn{5}{|c|}{ OSC } \\
\hline & & AIESEC & $\begin{array}{c}\text { OXFAN } \\
\text { INTERMÓN }\end{array}$ & $\begin{array}{c}\text { Acción } \\
\text { ciudadana }\end{array}$ & $\begin{array}{l}\text { Fundación } \\
\text { superación }\end{array}$ & $\begin{array}{l}\text { Manos } \\
\text { unidas }\end{array}$ \\
\hline \multirow{3}{*}{ Protección } & Defender & & $\sqrt{ }$ & & & \\
\hline & Denunciar & & $\sqrt{ }$ & & $\sqrt{ }$ & $\sqrt{ }$ \\
\hline & Movilización & $\sqrt{ }$ & $\sqrt{ }$ & & $\sqrt{ }$ & \\
\hline \multirow{2}{*}{ Monitoreo } & Supervisar & & $\sqrt{ }$ & & & \\
\hline & Promover & $\sqrt{ }$ & $\sqrt{ }$ & & $\checkmark$ & $\sqrt{ }$ \\
\hline \multirow{7}{*}{ Abogacía } & $\begin{array}{l}\text { Difusión de la } \\
\text { información }\end{array}$ & $\sqrt{ }$ & $\sqrt{ }$ & $\sqrt{ }$ & & $v$ \\
\hline & Comentar & $\sqrt{ }$ & $\sqrt{ }$ & $\checkmark$ & & $\sqrt{ }$ \\
\hline & Dialogar & $\sqrt{ }$ & $\sqrt{ }$ & & $\checkmark$ & $\sqrt{ }$ \\
\hline & Negociar & & $\sqrt{ }$ & & $\checkmark$ & $\mathcal{V}$ \\
\hline & $\begin{array}{c}\text { Incidencia } \\
\text { Política }\end{array}$ & & $\sqrt{ }$ & 7 & & \\
\hline & Sensibilizar & $\sqrt{ }$ & $\sqrt{ }$ & $\sqrt{ }$ & & $\sqrt{ }$ \\
\hline & Participar & & $\sqrt{ }$ & $\sqrt{ }$ & $\sqrt{ }$ & \\
\hline \multirow{2}{*}{ Intermediación } & $\begin{array}{c}\text { Generación de } \\
\text { redes }\end{array}$ & $v$ & $\checkmark$ & $\sqrt{ }$ & $\sqrt{ }$ & $\checkmark$ \\
\hline & $\begin{array}{c}\text { Representación } \\
\text { ciudadanía }\end{array}$ & $\checkmark$ & v & & $\sqrt{ }$ & \\
\hline \multirow{3}{*}{$\begin{array}{c}\text { Cohesión } \\
\text { social }\end{array}$} & $\begin{array}{l}\text { Creación de } \\
\text { comunidad }\end{array}$ & $\checkmark$ & $\sqrt{ }$ & & & $\checkmark$ \\
\hline & $\begin{array}{c}\text { Empoderamiento } \\
\text { ciudadano }\end{array}$ & $\sqrt{ }$ & $\sqrt{ }$ & $\sqrt{ }$ & & 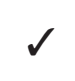 \\
\hline & $\begin{array}{c}\text { Transmisión } \\
\text { de valores }\end{array}$ & $\sqrt{ }$ & $\sqrt{ }$ & $\sqrt{ }$ & $\sqrt{ }$ & $\checkmark$ \\
\hline \multirow{4}{*}{$\begin{array}{c}\text { Prestación de } \\
\text { servicios }\end{array}$} & Socialización & $\sqrt{ }$ & $\sqrt{ }$ & & $\sqrt{ }$ & $\sqrt{ }$ \\
\hline & $\begin{array}{c}\text { Trabajo en } \\
\text { comunidades }\end{array}$ & v & v & $\checkmark$ & & $\sqrt{ }$ \\
\hline & $\begin{array}{l}\text { Asistencia } \\
\text { ciudadana }\end{array}$ & $\sqrt{ }$ & $\sqrt{ }$ & $\sqrt{ }$ & & $\sqrt{ }$ \\
\hline & Pedagogía & & $\sqrt{ }$ & $\checkmark$ & & $\checkmark$ \\
\hline
\end{tabular}

Fuente: Elaboración propia. 
en 2014 se registraron más de 2.000 muertes. En Colombia se registraron 848 feminicidios en 2015, 902 en 2016 y 940 en 2017. Es decir, en tres años 2.690 mujeres fueron asesinadas (ONU, 2018b).

Desde la Convención sobre la eliminación de todas las formas de discriminación contra la mujer (CEDAW) y la Declaración sobre la eliminación de la violencia, se reconoció que la violación de los derechos de un ser humano por el hecho de ser mujer es un asunto que no debe ser tratado sólo por el Estado. Como problema de derechos humanos, el feminicidio permite apelar a las cortes internacionales para encontrar el castigo y la reparación pertinente a la gravedad de los hechos. La agresión contra una mujer guarda una relación directa con la violencia y discriminación por motivo de género. En las últimas décadas, se ha evidenciado un avance tanto para la garantía como para la protección de dichos derechos. Sin embargo, las mujeres continúan siendo víctimas, lo cual tiene repercusiones individuales y sociales.

En este caso, las funciones de protección, defensa y monitoreo que adelantan organizaciones como Casa del Encuentro (Argentina), Colectivo Mujeres de Negro (Argentina), Paro Internacional de las Mujeres (Argentina, Bolivia, Brasil, Chile, Guatemala, Uruguay, Paraguay, Puerto Rico, Nicaragua), ELA (Argentina), FEIM (Argentina), implican acciones como la denuncia y la defensa de las mujeres ante las autoridades competentes de cada país.

$\mathrm{Al}$ interior de estas organizaciones se destacan funciones encaminadas hacia la movilización, especialmente para a salir a la calle. Esta es una manera de visibilizar la denuncia para defender y eliminar delitos como el feminicidio. En la medida en que con estas acciones se rechazan los vejámenes y todo tipo de violencia de género, también se está cumpliendo con la función de protección. A su vez, se resaltan las funciones de intermediación, debido a que todas las OSC del estudio realizan acciones de cooperación y capacitación con otras organizaciones sociales, con el objetivo de sensibilizar, informar y capacitar sobre prevención.

Igualmente, fueron encontrados hallazgos en materia de difusión de la información y de acciones como comentar, participar, empoderar a los ciudadanos y la trasmisión de valores. Para ello, las organizaciones analizadas hacen uso de espacios como las mesas de trabajo de atención a las mujeres víctimas, con el fin de encontrar puntos de vista que permitan atender y prevenir el problema de violencia de género. También 
se encontró que todas las OSC desarrollan campañas en contra de la violencia de género y fomentan acciones de abogacía.

En la matriz 3 se observa que en el accionar de las OSC, la abogacía para la participación política es escasa en materia de formulación e implementación de las políticas públicas de género. Igualmente, se identificó que algunas organizaciones como Paro Internacional de las Mujeres, ELA, FEIM no prestan servicios que empoderen grupos de apoyo en las comunidades. Nótese que las OSC no necesariamente han de cumplir con todas las funciones, pero sí es importante identificar cuál es su accionar.

\section{Defensores de los derechos humanos vulnerables y vulnerados}

El exterminio a los líderes sociales es una realidad en el mundo y tiene énfasis en AL. En la segunda década del siglo XXI se han registrado las cifras más altas de asesinato de defensores de los DDHH. De los 312 asesinatos a defensores de los DDHH en 2017, 212 ocurrieron en la región (Front Line Defenders, 2017, p. 12). Entre estos, 126 ocurrieron en Colombia (Marín-Aranguren \& Trejos-Mateus, 2018). Es decir, en 2017 fueron asesinados 34 líderes más que el año anterior en Latinoamérica. Para el primer semestre del 2018, solo en Colombia, la tasa de homicidios registrada fue de un líder cada 35 horas. Es decir, se registraron 123 muertes los primeros meses de este año (Chica García, 2018). Lo que es claro es que "Ochenta y cuatro por ciento de los defensores de derechos humanos asesinados habían recibido al menos una amenaza previa a su muerte relacionada a su activismo y, pese a los indicios dejados por los agresores, solo en el $12 \%$ de los casos se dio arresto a las personas sospechosas o responsables de los crímenes" (González, 2018, p. 1).

Claramente, el caso más relevante es el de Colombia. Al acumular el $50 \%$ de los asesinatos de los defensores de DDHH de la región, se ha denominado como "el país más mortífero de Latinoamérica” (Amnistía Internacional, 2018). El infortunado segundo puesto lo ocupa Brasil con el $40 \%$ de homicidios, y le siguen México y Venezuela. Amnistía Internacional (2018) discute las cifras respecto a Venezuela, donde oficialmente el reporte es de un solo líder social asesinado en 2017, pero esta organización hace referencia a 110 muertos y una oleada de presos políticos que supera los 250.

En varias ocasiones, la ONU (2018a) ha advertido que los defensores han sido víctimas de violación de derechos humanos en todos los países de la región, y ha reconocido el limitado ambiente habilitante con el que se 
Matriz 3: Evaluación del accionar de las OSC en la lucha por los derechos de las mujeres

\begin{tabular}{|c|c|c|c|c|c|c|}
\hline \multirow[b]{2}{*}{ Funciones } & \multirow{2}{*}{$\begin{array}{l}\text { Acciones } \\
\text { /OSG }\end{array}$} & \multicolumn{5}{|c|}{ OSC } \\
\hline & & $\begin{array}{c}\text { Casa del } \\
\text { encuentro }\end{array}$ & $\begin{array}{c}\text { Colectivo } \\
\text { Mujeres } \\
\text { de Negro }\end{array}$ & $\begin{array}{c}\text { Paro } \\
\text { internacional } \\
\text { de mujeres }\end{array}$ & Ela* & Feim** \\
\hline \multirow{3}{*}{ Protección } & Defender & $\sqrt{ }$ & $\sqrt{ }$ & $\sqrt{ }$ & $\checkmark$ & $\sqrt{ }$ \\
\hline & Denunciar & $\sqrt{ }$ & $\sqrt{ }$ & $\sqrt{ }$ & $\checkmark$ & $\checkmark$ \\
\hline & Movilización & $\sqrt{ }$ & $\checkmark$ & $\checkmark$ & & $\sqrt{ }$ \\
\hline \multirow{2}{*}{ Monitoreo } & Supervisar & $\checkmark$ & $\checkmark$ & & & \\
\hline & Promover & $\sqrt{ }$ & $\checkmark$ & $\sqrt{ }$ & $\checkmark$ & $\checkmark$ \\
\hline \multirow{7}{*}{ Abogacía } & $\begin{array}{l}\text { Difusión de la } \\
\text { información }\end{array}$ & $\sqrt{ }$ & & $\sqrt{ }$ & & $\sqrt{ }$ \\
\hline & Comentar & $\sqrt{ }$ & $\sqrt{ }$ & $\sqrt{ }$ & $\checkmark$ & $\sqrt{ }$ \\
\hline & Dialogar & $\sqrt{ }$ & $\sqrt{ }$ & & & $\sqrt{ }$ \\
\hline & Negociar & $\checkmark$ & & & $\sqrt{ }$ & $\sqrt{ }$ \\
\hline & $\begin{array}{c}\text { Incidencia } \\
\text { Política }\end{array}$ & $\checkmark$ & & & & \\
\hline & Sensibilizar & $\sqrt{ }$ & $\sqrt{ }$ & $\sqrt{ }$ & & $\sqrt{ }$ \\
\hline & Participar & $\sqrt{ }$ & $\checkmark$ & $\sqrt{ }$ & $\checkmark$ & \\
\hline \multirow{2}{*}{ Intermediación } & $\begin{array}{c}\text { Generación de } \\
\text { redes }\end{array}$ & $\sqrt{ }$ & & $\sqrt{ }$ & $\checkmark$ & \\
\hline & $\begin{array}{l}\text { Representación } \\
\text { ciudadanía }\end{array}$ & $\sqrt{ }$ & & $\sqrt{ }$ & & \\
\hline \multirow{3}{*}{$\begin{array}{l}\text { Cohesión } \\
\text { social }\end{array}$} & $\begin{array}{l}\text { Creación de } \\
\text { comunidad }\end{array}$ & $\sqrt{ }$ & $\sqrt{ }$ & $\sqrt{ }$ & & $\checkmark$ \\
\hline & $\begin{array}{c}\text { Empoderamiento } \\
\text { ciudadano }\end{array}$ & $\sqrt{ }$ & & $\sqrt{ }$ & & \\
\hline & $\begin{array}{c}\text { Transmisión } \\
\text { de valores }\end{array}$ & $\sqrt{ }$ & $\checkmark$ & $\sqrt{ }$ & & \\
\hline \multirow{4}{*}{$\begin{array}{c}\text { Prestación de } \\
\text { servicios }\end{array}$} & Socialización & $\checkmark$ & $\checkmark$ & & $\checkmark$ & $\checkmark$ \\
\hline & $\begin{array}{c}\text { Trabajo en } \\
\text { comunidades }\end{array}$ & $\sqrt{ }$ & & & & \\
\hline & $\begin{array}{l}\text { Asistencia } \\
\text { ciudadana }\end{array}$ & $\sqrt{ }$ & $\sqrt{ }$ & & & $\checkmark$ \\
\hline & Pedagogía & $\mathcal{V}$ & & & & $\mathcal{V}$ \\
\hline
\end{tabular}

Fuente: Elaboración propia.

*Equipo Latinoamericano de Justicia y Género

**Fundación para el Estudio e Investigación de la Mujer (FEIM) 
cuenta en Latinoamérica. Los activistas han sido víctimas de detenciones arbitrarias, tortura, calumnia, intimidaciones, amenazas, entre otros vejámenes. Este tipo de maltratos en contra de los defensores va en contravía del derecho internacional y de las mismas normas nacionales. Con la Declaración sobre Defensores de los Derechos Humanos de la ONU se estableció que, toda persona tiene derecho a promover y procurar por la protección de los derechos y libertades.

En esta última variable de análisis, se encontró la participación de las OSC Amnistía Internacional, Asocia, Front Defenders, CCONG y Think Thank Civismo, para la creación de espacios de protección y defensa de personas defensoras de derechos humanos. Por esto, se destaca que estas organizaciones tienen un desarrollo amplio en las siete funciones básicas, aunque en diferente medida, tal como se puede evidenciar en la matriz 4.

Por ejemplo, En términos de denuncia, Front Line Defenders ofrece la ayuda necesaria para quienes se encuentra en peligro inmediato. Esta OSC dispone de una línea telefónica a través de la cual el defensor puede solicitar ayuda en cualquier momento y facilitar su reubicación. Además, son desarrollados programas de capacitación para garantizar la seguridad y protección de los defensores. Igualmente, son realizados talleres, cursos, seminarios, en los cuales se intercambian experiencias y conocimientos como herramientas adicionales que puedan ayudarles en el ámbito personal. Dicha capacitación, cubre aspectos generales del análisis de amenazas y la reacción frente a incidentes de seguridad. En materia de difusión de la información, las organizaciones del estudio han documentado ataques contra los defensores con el propósito de visibilizar esta situación.

Asimismo, se encontró que estas OSC trabajan en la generación de redes de apoyo, las cuales han establecido mecanismos de vigilancia, para que en los casos en los que se presente violación de derechos humanos, se informe con rapidez. Es importante aclarar que, si bien la incidencia política es una práctica desarrollada por la mayoría de las OSC analizadas, falta trabajo en el fortalecimiento de las medidas impulsadas para la plena protección, de modo que las víctimas puedan acceder a la reparación.

En términos de prestación de servicios, se reconoce el trabajo en pedagogía, pero se evidencian restricciones en la prestación de otro tipo de asistencia que es decisiva para la recuperación de quienes han sido vulnerados. La Oficina del Alto Comisionado de las Naciones para los Derechos Humanos anotan que "los medios podrían realizar esfuerzos especiales para contrarrestar todo intento de calumniar a los defensores 
Matriz 4: Evaluación del accionar de las OSC por los DDHH y la erradicación de la violencia

\begin{tabular}{|c|c|c|c|c|c|c|}
\hline \multirow[b]{2}{*}{ Funciones } & \multirow[b]{2}{*}{$\begin{array}{l}\text { Acciones } \\
\text { /OSC }\end{array}$} & \multicolumn{5}{|c|}{ OSC } \\
\hline & & $\begin{array}{l}\text { Amnistía } \\
\text { Internacional }\end{array}$ & $\begin{array}{l}\text { Asocia } \\
2030\end{array}$ & $\begin{array}{c}\text { Front } \\
\text { Defenders }\end{array}$ & CCONG* & $\begin{array}{l}\text { Think } \\
\text { Tank } \\
\text { Civismo }\end{array}$ \\
\hline \multirow{3}{*}{ Protección } & Defender & $\checkmark$ & $\checkmark$ & $\checkmark$ & $\checkmark$ & $\checkmark$ \\
\hline & Denunciar & $\checkmark$ & $\checkmark$ & $\checkmark$ & $\checkmark$ & $\checkmark$ \\
\hline & Movilización & $\checkmark$ & $\checkmark$ & $\checkmark$ & & $\checkmark$ \\
\hline \multirow{2}{*}{ Monitoreo } & Supervisar & $\checkmark$ & $\sqrt{ }$ & & & \\
\hline & Promover & $\checkmark$ & $\checkmark$ & $\checkmark$ & $\checkmark$ & $\sqrt{ }$ \\
\hline \multirow{7}{*}{ Abogacía } & $\begin{array}{l}\text { Difusión de la } \\
\text { información }\end{array}$ & $\checkmark$ & $\sqrt{ }$ & $\checkmark$ & $\sqrt{ }$ & $\checkmark$ \\
\hline & Comentar & $\sqrt{ }$ & $\checkmark$ & $\sqrt{ }$ & $\checkmark$ & $\sqrt{ }$ \\
\hline & Dialogar & $\checkmark$ & $\checkmark$ & & & $\checkmark$ \\
\hline & Negociar & $\checkmark$ & & & $\checkmark$ & $\checkmark$ \\
\hline & $\begin{array}{c}\text { Incidencia } \\
\text { Política }\end{array}$ & $\checkmark$ & $\sqrt{ }$ & & $\checkmark$ & \\
\hline & Sensibilizar & $\checkmark$ & $\checkmark$ & $\checkmark$ & & $\checkmark$ \\
\hline & Participar & $\checkmark$ & $\checkmark$ & $\checkmark$ & $\checkmark$ & \\
\hline \multirow{2}{*}{ Intermediación } & $\begin{array}{c}\text { Generación de } \\
\text { redes }\end{array}$ & $\checkmark$ & $\sqrt{ }$ & $\checkmark$ & $\checkmark$ & $\checkmark$ \\
\hline & $\begin{array}{l}\text { Representación } \\
\text { ciudadanía }\end{array}$ & $\checkmark$ & $\checkmark$ & $\checkmark$ & & $\checkmark$ \\
\hline \multirow{3}{*}{$\begin{array}{l}\text { Cohesión } \\
\text { social }\end{array}$} & $\begin{array}{l}\text { Creación de } \\
\text { comunidad }\end{array}$ & $\checkmark$ & $\checkmark$ & $\checkmark$ & & $\sqrt{ }$ \\
\hline & $\begin{array}{c}\text { Empoderamiento } \\
\text { ciudadano }\end{array}$ & $\checkmark$ & $\checkmark$ & $\checkmark$ & & $\checkmark$ \\
\hline & $\begin{array}{c}\text { Transmisión } \\
\text { de valores }\end{array}$ & $\checkmark$ & $\checkmark$ & $\checkmark$ & & $\checkmark$ \\
\hline \multirow{4}{*}{$\begin{array}{l}\text { Prestación de } \\
\text { servicios }\end{array}$} & Socialización & $\checkmark$ & $\checkmark$ & $\checkmark$ & $\checkmark$ & $\sqrt{ }$ \\
\hline & $\begin{array}{c}\text { Trabajo en } \\
\text { comunidades }\end{array}$ & $\checkmark$ & $\checkmark$ & $\checkmark$ & & $\checkmark$ \\
\hline & $\begin{array}{l}\text { Asistencia } \\
\text { ciudadana }\end{array}$ & $\checkmark$ & $\checkmark$ & $\checkmark$ & & $\checkmark$ \\
\hline & Pedagogía & $\checkmark$ & $\checkmark$ & & & \\
\hline
\end{tabular}

Fuente: Elaboración propia.

*Confederación Colombiana de ONG (CCONG) 
de los derechos humanos, por ejemplo, saliendo rápidamente al paso de declaraciones en las que se los acuse falsamente de terroristas, delincuentes o enemigos del Estado" (ONU, 2004, p. 36).

\section{IMPUNIDAD: EL PUNTO EN COMÚN}

A pesar de todas las vulneraciones señaladas antes, en la región se registra la mayor impunidad del mundo. Seis de los diez países peor posicionados en temas de transparencia y justicia están en Latinoamérica. Según el Índice Global de Impunidad (2018) ${ }^{4}$ México es catalogado como el país latinoamericano con mayor impunidad (con 69,21 puntos) y el cuarto a nivel mundial. Siguen Venezuela con 67,24; Perú con 69,04 y Brasil con 66,72. Colombia ocupa el octavo puesto a nivel mundial con 66,57 puntos, seguido por Nicaragua con 66,34.

Así, se concluye que la violación de los DDHH en la región se fortalece debido a la ausencia del castigo. En este sentido, se puede entender que las OSC latinoamericanas tengan un accionar más reactivo que proactivo. Así pues, estas organizaciones han enfocado sus esfuerzos en comunicar, mediar, negociar, prestar servicios de apoyo a la población y ser voceros de la ciudadanía, más que en intentar proteger y salvaguardar los DDHH. Debido a los altos niveles de impunidad, a las OSC les es más útil comunicar lo que sucede, apoyar a la sociedad y prestar los servicios necesarios de mediación para evitar casos similares en el futuro. Es así como su reacción y actuación ante los acontecimientos les permite avanzar cada vez más en el balance entre actuar para prevenir (antes de) y actuar para brindar asistencia (después de).

Lo anterior se evidencia a través de la investigación realizada a las 20 organizaciones analizadas en las 4 matrices anteriores. En el marco legal y de trabajo constante con entes gubernamentales nacionales e internacionales y empresas, ellas comentaron, meditaron y negociaron las garantías para salvaguardar los DDHH de los ciudadanos latinoamericanos.

A continuación, se expone el accionar de las OSC en pro de la protección de los DDHH en AL, en las cuatro variables analizadas: 


\section{Seguridad alimentaria}

El 26 de abril de 2013, se aprueba la Estrategia de la FAO para realizar alianzas eficaces con las OSC en temas estratégicos de seguridad alimentaria. Así, se reconocen seis funciones principales en el trabajo FAOOSC (ver tabla 2):

Tabla 2. Funciones principales del trabajo FAO-OSC en pro de la seguridad alimentaria

\begin{tabular}{|c|c|}
\hline Programa de Campo & $\begin{array}{c}\text { Incluir a las OSC en la planificación y ejecución de } \\
\text { actividades sobre el terreno. }\end{array}$ \\
\hline $\begin{array}{l}\text { Intercambio de } \\
\text { conocimientos y análisis de } \\
\text { información }\end{array}$ & $\begin{array}{c}\text { Las OSC son fundamentales para los programas de } \\
\text { información y educación encaminados a sensibilizar a la } \\
\text { opinión pública. }\end{array}$ \\
\hline Creación de capacidad & $\begin{array}{l}\text { Garantizar que las voces de los grupos afectados sean } \\
\text { escuchadas en los espacios de toma de decisiones. }\end{array}$ \\
\hline $\begin{array}{l}\text { Utilización conjunta de } \\
\text { recursos en situaciones de } \\
\text { emergencia }\end{array}$ & $\begin{array}{l}\text { Financiación, mediación, diálogo, recomendaciones y } \\
\text { campañas. }\end{array}$ \\
\hline Diálogo sobre políticas & $\begin{array}{l}\text { Establecer las bases de un mecanismo de participación } \\
\text { para la implementación regional del Objetivo de Desarrollo } \\
\text { Sostenible número 1: Fin de la pobreza. }\end{array}$ \\
\hline $\begin{array}{l}\text { Actividades normativas, } \\
\text { promoción y comunicación }\end{array}$ & Procesos de consultas a diferentes niveles con las minorías. \\
\hline
\end{tabular}

Fuente: Elaboración propia con datos de (FAO, 2018).

En octubre de 2012, la FAO organizó el primer Foro Anual del Mecanismo de la Sociedad Civil, el cual reunió a 150 representantes de distintas regiones. Este encuentro tenía como fin la preparación para la participación en el Comité de Seguridad Alimentaria Mundial (CSA) que realizó la ONU (Roma, 12 al 15 de octubre de 2015). Allí participaron 96 OSC distribuidas de la siguiente manera: 2 organizaciones internacionales de investigación agrícola, 2 instituciones financieras internacionales y regionales, 68 asociaciones del sector privado, 2 fundaciones benéficas privadas y 47 observadores (CSA, 2017).

En el año 2013, Kellogg lanzó el Programa Desayunos para Mejores Días ${ }^{\circledR}$, con el objetivo de brindar un desayuno energético a los niños y sus familias (Kellogg, 2019). En la región, se crearon alianzas con bancos de alimentos e instituciones de 14 países. Dentro de las alianzas más importantes, se destacan: 
- Programa de Desayuno Saludable (Colombia). Con este programa se logró ofrecer desayunos completos diarios a 3.300 niños en alianza con la Asociación de Bancos de Alimentos de Colombia (ABACO) e importantes productores lácteos.

- Desayunos para Mejores Días (México). En alianza con la Fundación para la Protección de la Niñez (IAP) y 91 OSC, la empresa donó 2,6 millones de porciones de cereal y snacks con los cuales apoyó a más de 7 mil niños y adultos mayores (Kellogg, 2019).

Entre las campañas más importantes de la organización en AL se destacan:

1. "El Show del Hambre" (junio de 2018): Campaña en colaboración con David De María, enfocada a conseguir fondos para luchar contra la desnutrición infantil ${ }^{5}$. En la estrategia se establece que, si se donan 6 euros, es posible entregar un tratamiento de leche terapéutica para un niño, durante una semana; si son 10 euros, se puede alcanzar un tratamiento nutricional por una semana; si son 36 euros, un niño podrá recibir leche terapéutica por seis semanas; y si la donación es de 40 euros, una familia tendrá agua segura.

2. "Restaurantes contra el hambre" (10 Oct a 30 Nov 2017): Es una iniciativa solidaria contra la desnutrición infantil en Colombia. En esta participan prestigiosos restaurantes y chefs del país. Esta campaña fue realizada en tres países de la región: Guatemala, Perú y Colombia. Para 2017, "La Fundación Éxito se une a Acción contra el Hambre como organizador con su meta GEN $\mathrm{CERO}^{6}$, para que en el 2030 el país tenga la primera generación con cero desnutriciones crónicas. Además, se contó con el respaldo de Acodres (Asociación Colombiana de Restaurantes) y de domicilios.com" (Acción Contra el Hambre, 2017, p. 1).

Según los datos proporcionados por Acción Contra el Hambre, gracias a la campaña, en 2017 se mejoró la calidad de vida y la seguridad nutricional de más de 475 mil personas en Colombia.

5 Cantautor y compositor español.

6 Movimiento nacional liderado desde el año 2013 por el Grupo Éxito a través de su Fundación para lograr erradicar la desnutrición crónica en los niños menores de cinco años en Colombia para el año 2030 . 


\section{Pobreza y Desigualdad}

Uno de los temas que más apremia a la región es la disminución de las brechas entre los sectores de la sociedad. Los registros indican que los ingresos de las personas más ricas son nueve veces mayores que los ingresos de las más pobres (CEPAL, 2018a, p. 44). La realidad es que el accionar de las OSC en la lucha contra la pobreza y la desigualdad es amplio. Este proceso parte de la inclusión del tema en la agenda pública y atraviesa el ciclo de política pública. Sin embargo, se requiere una mayor intervención porque la desigualdad sigue en el número uno de los temas de agenda.

Organizaciones como OXFAM INTERMÓN interactúa a nivel internacional con pares como la Red Latinoamericana sobre Deuda, Desarrollo y Derechos (LATINDA) y el Instituto Centroamericano de Estudios Fiscales (ICEFI). Esta asociación de OSC presentaron "DataIgualdad", la primera plataforma digital de libre acceso sobre política fiscal, desigualdad y derechos en América Latina y el Caribe. En asocio con el Banco Mundial, la plataforma contiene más de 70 indicadores para 18 países de la región Súbela Radio (2019).

El impacto positivo de Oxfam en la región se enlista en dos hechos principales:

1. La Calculadora para medir las desigualdades (junio 2016): La organización junto con Ojo Público7 crean una original calculadora de la desigualdad en América Latina. Este instrumento le permite a cualquier ciudadano de 15 países latinoamericanos dividir el ingreso mensual de su hogar entre los miembros que lo conforman, para compararlo después con el resto de la población de su país. De este modo, es posible calcular el tiempo necesario para obtener los ingresos mensuales de un multimillonario, de un grupo de ingreso bajo, medio bajo, medio y alto, según la clasificación de la organización.

2. Privilegios que niegan derechos: Se trata de una denuncia dirigida a la región. Se estima que tomando los datos entre 2011 y el estimado hasta 2019, si se redujera la desigualdad en 5 puntos, cerca de 17,4 millones de personas podrían salir de la pobreza. 


\section{Violencia: feminicidios y asesinatos de defensores de los DDHH.}

A continuación, relacionamos cuatro acciones de algunas OSC en materia de protección y denuncia de la violencia contra las mujeres y los defensores de los DDHH:

Conmuévete y Muévete: se trata de una campaña organizada por la batucada feminista La Tremenda Revoltosa para sensibilizar contra los feminicidios y asesinatos de líderes sociales. Lanzada el 25 de julio de 2017 en Bogotá, esta campaña se dividió en dos etapas principales: 1) difundir y conocer de primera mano los asesinatos de líderes y lideresas sociales, así como los feminicidios que han ocurrido en el país. 2) promover la movilización social. La principal razón que motivo el movimiento fue la indiferencia de la sociedad frente a cifras tales como el asesinato de más de 366 mujeres y de 52 líderes y lideresas sociales para julio de 2017. (Contagio Radio, 2017).

Ni una menos: el movimiento "Ni una mujer menos, ni una muerta más" nació el 3 de junio de $2015^{8}$. Conformado por un grupo de periodistas, activistas y artistas en Argentina, este movimiento se extendió hasta convertirse en una campaña colectiva de ciudadanos por todo el mundo. Países como Uruguay, Perú, Italia, Colombia, Chile, Ecuador, Bolivia, Paraguay, Venezuela, México, Portugal, España y Francia se han unido al movimiento.

Iniciativa Spotlight: esta iniciativa impulsada por la Unión Europea (UE) y la ONU para la eliminación de la violencia contra las mujeres y niñas en América Latina, está concentrada principalmente en el feminicidio. Fue lanzada el 27 de septiembre 2018 e implementada en cinco países (Argentina, El Salvador, Guatemala, Honduras y México). La iniciativa se preocupa por motivar la participación conjunta de gobiernos y sociedad civil.

La Casa del Encuentro: esta asociación civil defiende los DDHH de las mujeres en Argentina. Entre sus logros se destacan: la creación del "Centro de Asistencia, Orientación y Prevención Integral en Violencia sexista y trata de personas de la Asociación Civil La Casa del Encuentro. Así mismo, en el año 2012, realizó aportes legislativos logrando la modificación del Código Penal de la Nación, con la incorporación de la

8 Susana Chávez Castillo, poeta y activista mexicana asesinada en 2011 por denunciar los crímenes contra las mujeres en su país, fue la autora de esta frase en 1995. 
figura de "femicidio" en el art. 80 inc. 11 del C.P.N. Esto permitió agravar la pena para los casos en que el homicidio fuere perpetrado por un hombre, hacia una mujer, mediando violencia de género.

\section{Protección de los defensores de DDHH}

A continuación, describimos varias de las acciones más relevantes de las OSC en materia de protección de los líderes defensores de DDHH:

\section{Unidos por la protección de los líderes y defensores de derechos} humanos (2018): la Consejera Presidencial para los Derechos Humanos, Paula Gaviria Betancur, afirmó que, en junio de ese año, el Estado colombiano, empresas y OSC firmaron una declaración conjunta en la que se comprometieron a trabajar en la protección de la vida e integridad de los líderes y defensores de derechos humanos. "Los derechos humanos de los defensores y líderes debe ser la prioridad para el Estado, las empresas y las organizaciones de la sociedad civil”. Grupos de la OSC como PRODECO reafirmaron su interés y rol activo por la protección de los derechos humanos.

Lidera La Vida (18 julio de 2018): La Procuraduría General de la Nación, Defensoría del Pueblo, Noticias Caracol, El Espectador, Blue Radio, la Consultoría para los Derechos Humanos y el Desplazamiento (CODHES), la Organización Nacional Indígena de Colombia (ONIC), la Asociación Nacional de Afrocolombianos Desplazados (AFRODES), la Pastoral Social, el Instituto de Estudios del Ministerio Público y el Programa de Justicia de la Agencia de los Estados Unidos para el Desarrollo Internacional (USAID), lanzaron la Campaña Lidera La Vida, frente al asesinato de líderes sociales en Colombia, con el fin de sensibilizar a la opinión pública (CODHES, 2018).

Impulso a la ley general para la prevención, protección, investigación y reparación integral para personas defensoras de los derechos humanos y periodistas (25 octubre de 2018): 130 organizaciones mexicanas, 22 internacionales y más de 600 personas impulsan la iniciativa. Entre las OSC participantes, se destacan: Promoción y Defensa de los Derechos Humanos (Mérida); Instituto Mexicano de Derechos Humanos y Democracia (México); Promoción y Defensa de los Derechos Humanos (Mérida); y el Instituto Mexicano de Derechos Humanos y Democracia (México). 


\section{Informe Políticas públicas eficaces para el derecho a defender}

los derechos humanos (18 de octubre de 2018): presentado en México, evidencia la preocupación de las OSC por extender su campo de acción para la protección e implementación de mecanismos en pro de los Defensores y Defensoras de Derechos Humanos. La estrategia liderada por Protection International (PI) y el Centro por la Justicia y el Derecho Internacional (CEJIL), hace un llamado para lograr la articulación entre las OSC y los actores gubernamentales, para que se genere una revisión desde arriba hacia abajo de los mecanismos de protección existentes. Esto debe dar lugar a lo que fue llamado una “ipolítica pública ya!", basada en pilares como la justicia y la verdad.

\section{CONGLUSIONES}

Lo que la investigación permite advertir es que en la región los Estados son grandes ratificadores de tratados sobre derechos humanos, pero la implementación es poco evidente. Por este motivo las OSC han liderado procesos continuos para la promoción y defensa de estos. Luego de hacer un recorrido por el accionar de 100 OSC en América Latina, se evidenció que éstas han cumplido principalmente dos funciones de las señaladas por el Banco Mundial:

\section{Difusión de la información para sensibilizar a los actores} interesados. Se trata de la función más implementada en la región. Comprende la generación o articulación de redes con otras organizaciones sociales u ONG para hacer públicos los temas que se quieren denunciar. En sus informes, estas organizaciones denuncian violaciones, así como sensibilizan y movilizan masas a través de campañas. Igualmente, las OSC realizan actividades como: publicación de estudios, organización de seminarios, foros y encuentros para discutir la protección de los DDHH o la violación de estos, además de denuncias públicas, y trabajos de empoderamiento ciudadano a través de la educación. Sin embargo, las OSC aún carecen de estrategias concretas para incidir en la toma de decisiones de los distintos organismos encargados del diseño e implementación de políticas públicas destinadas a combatir las violaciones de los derechos fundamentales. 
2. Abogacía o defensa. Las OSC adelantan un trabajo de interacción con el Estado, basado en la construcción de relaciones con organizaciones intergubernamentales, entidades estatales nacionales (en distintos niveles), así como con organizaciones pares no gubernamentales a nivel internacional y organizaciones de base. Esta creación de redes se relaciona con acciones como la organización de convocatorias y/o conversatorios en los que se diseñan, ejecutan, evalúan e incluso se proponen políticas públicas. Estas interacciones con el Estado son ambivalentes, resultando algunas veces en prácticas de cooperación y complementación, mientras que en otras predomina la confrontación.

Por lo anterior, se considera que las OSC son difusoras de información jugando un rol complementario en la ayuda a las víctimas. Sin embargo, se debe resaltar que aún hay actividades que requieren el involucramiento de las OSC para prestar una amplia gama de servicios a las víctimas. La realidad es que las OSC han ayudado mediante la prestación de servicios en situaciones de crisis.

En estos últimos años, las OSC han fortalecido sus funciones, capacidades y habilidades para comentar, meditar y negociar las políticas para la garantía de los DDHH. En este sentido, las OSC del estudio recorrieron varios caminos para que en los Objetivos de Desarrollo Sostenible (ODS) quedaran incluidos los temas de las cuatro variables analizadas 9 . Sus propuestas han sido parte activa en la formulación de la Agenda 2030. Tal es el caso de Asocia 2030, una alianza chilena que ha incidido en la toma de decisiones de política pública para la implementación de dicha Agenda. Igualmente, campañas como "Yo opino, es mi derecho 2017" han sido ejemplo en la región ${ }^{10}$. Esto debido a su gran impacto, pues fue realizada en el $94,5 \%$ de las comunas chilenas,

\footnotetext{
9 Los ODS son 17 metas globales enfocadas en lograr un futuro mejor, a través de cambios positivos en pro de mejorar la calidad de vida de las personas y cuidar el planeta. Estos principios básicos se pusieron en marcha en el 2016 y engloban varios de los temas que aquí conciernen: ODS1, Fin de la pobreza; ODS2, Hambre Cero; ODS3, Salud y Bienestar; ODS4, Educación de Calidad; ODS5, Igualdad de Género; ODS8, Trabajo decente y crecimiento económico; ODS10, Reducción de las desigualdades; ODS16, Paz, Justicia e Instituciones Sólidas. A través de la integración y cumplimiento de estos ODS se han sentado las bases de la Agenda 2030 que apunta a acabar con la pobreza, promover la prosperidad y el bienestar de todas las personas a través del desarrollo sostenible y protección del medio ambiente.

10 Iniciativa que tiene por objetivo generar un espacio para que los niños(as) y adolescentes, participen y expresen su visión respecto a los problemas que los afectan y pueden/deben ser tratados mediante los Objetivos de Desarrollo Sostenible(ODS).
} 
abarcando 3.965 establecimientos educacionales, en los que se reunió la voz de 659 mil niños y jóvenes entre 4 y 18 años (UNICEF, 2017). Mediante su participación, los niños más pequeños expresaron que los ODS más importantes para ellos son: Fin de la pobreza, Salud y bienestar, y alcanzar la paz y la justicia. Por su parte, los adolescentes señalaron que es necesario mejorar la calidad de la educación y luchar por una verdadera igualdad de género. (Gobierno de Chile, 2018, p. 9).

Finalmente, en la investigación se corroboró que las OSC se apoyan en las OIG para implementar lo que técnicamente se conoce como efecto bumerán, entendido como una de las formas por la que los recursos políticos disponibles para un actor pueden incrementarse gracias a sus vínculos internacionales ${ }^{11}$. De esta manera, logran activar mecanismos de veeduría al ejercer funciones de monitoreo, intermediación, abogacía y cohesión social. Es así como se convierten en agentes de cambio. En el periodo 2000-2018, se resalta la presencia y participación de las OSC que tienen mayor capacidad de incidencia. Este proceso las ha posicionado como actores con posibilidad de negociar, comentar y mediar. En este sentido, se evidencian acciones exitosas en la arena de la seguridad alimentaria, erradicación de la pobreza y la desigualdad, la lucha por los derechos de las mujeres y la erradicación de la violencia.

Los hallazgos de esta investigación dan cuenta de los espacios de sensibilización, difusión de información, negociación e incidencia en las políticas públicas, generados por las OSC para evitar la vulneración de derechos humanos. Igualmente, también muestra la presencia de dichas organizaciones en escenarios donde se empodera a la comunidad a través de la transmisión de valores y la difusión de derechos y deberes. Las campañas, estrategias, movilizaciones, marchas y plantones no pasan sin ser advertidos por los medios de comunicación y las redes sociales. De este modo se demuestra que existe un amplio frente de acción por parte de las OSC, lo que las convierte en un agente central, que siempre trabaja en red.

11 Este efecto se entiende en el ideal de que donde existe falta de importancia sobre temas esenciales por parte de quienes están en el poder, los vínculos construidos entre distintas organizaciones puede proveer al país de canales alternos de comunicación. De este modo se extiende el horizonte de sus preocupaciones a escenarios internacionales para que luego estas vuelvan a su propio país en forma de soluciones. Igualmente, este efecto permite que las preocupaciones locales se entienda ahora como problemas que afectan a varias naciones, y por ende, sean centro de atención y esfuerzos de los actores políticos/sociales/culutrales y económicos necesarios. Para mayor información ver: https://sites.google.com/site/wikioeinebrija/efectoboomerang 


\section{REFERENCIAS}

Acción Contra el Hambre . (2017). Restaurantes contra el hambre en Colombia. Recuperado de https://www.accioncontraelhambre.org/es/restaurantescontra-el-hambre-en-colombia

Agencia Anadolu. (30 de Abril de 2018). América Latina es la región más violenta del mundo. W Radio.

Recuperado de http://www.wradio.com.co/noticias/internacional/americalatina-es-la-region-mas-violenta-del-mundo/20180430/nota/3744152.aspx

Amarante, V., Galván, M., y Mancero, X. (2016). Desigualdad en América Latina: una medición global. Revista CEPAL, 118, 27-47. https://doi.org/10.18356/ ee343975-es

América Latina, no la más pobre pero sí la más desigual. (2018, 20 de abril). Noticias ONU. Recuperado de https://news.un.org/es/story/2018/04/1431712

Amnistía Internacional. (2018). La situación de los derechos humanos en el mundo (Informe 2017/18). Recuperado de https://www.amnesty.org/es/documents/pol10/6700/2018/es/

BBC News (2017) ¿Cuántos alimentos se desperdician en América Latina? Recuperado de https://bbc.com/mundo/noticias40674408-

BBC News (2018). Los 3 países con más hambre en América Latina. Recuperado de https://bbc.com/mundo/noticias- 45503585

BID. (2017). Líderes Empresariales y el BID llaman a reducir el desperdicio de alimentos en América Latina y el Caribe. Recuperado de https://www.iadb. org/es/noticias/lideres-empresariales-y-el-bid-llaman-reducir-el-desperdiciode-alimentos-en-america

Cadena, D. (2015, 8 de marzo). 22 Mujeres latinas que hicieron historia. BuzzFeed. Recuperado de https://www.buzzfeed.com/danielacadena/mujeres-historia

CEPAL. (2018a). La Ineficiencia de la desigualdad (37 Periodo de Sesiones). Recuperado de https://repositorio.cepal.org/bitstream/ handle/11362/43566/4/S1800302_es.pdf

CEPAL. (2018b). Panorama Social de América Latina, 2017. Recuperado de https:// repositorio.cepal.org/bitstream/handle/11362/42716/7/S1800002_es.pdf

CEPAL. (2018c). Al menos 2.795 mujeres fueron víctimas de feminicidio en 23 países de América Latina y el Caribe en 2017. Recuperado de https://www.cepal.org/es/comunicados/cepal-al-menos-2795-mujeres-fueronvictimas-feminicidio-23-paises-america-latina-caribe

Chica García, A. (2018, 15 de septiembre). El brutal exterminio de líderes sociales en Colombia y un proyecto artístico para visibilizarlos. Infobae. Recuperado de https://www.infobae.com/america/colombia/2018/09/15/el-brutalexterminio-de-lideres-sociales-en-colombia-y-un-proyecto-artistico-paravisibilizarlos/

CIDH. (2010). Informe del Consejo de Derechos Humanos. Nueva York: Naciones Unidas. 
CIDH. (2018). Comisión Interamericana de Derechos Humanos. Documentos básicos: Introducción.

Recuperado de: http://www.oas.org/es/cidh/mandato/Basicos/intro.asp

CIDH y OEA. (2017). Informe sobre pobreza y Derechos Humanos en las Américas.

Recuperado de http://www.oas.org/es/cidh/informes/pdfs/

PobrezaDDHH2017.pdf

CODHES. (2018). Lidera La Vida. Recuperado de

https://codhes.wordpress.com/2018/07/25/lideralavida/

Contagio Radio (2017). Conmuévete y muévete, una campaña contra los feminicidios y asesinatos de líderes. Recuperado de https://www. contagioradio.com/la-campana-que-movilizara-a-la-ciudadania-contra-losfeminicidios-y-asesinatos-de-lideres/

Comité de Seguridad Alimentaria Mundial. (2017). Evaluación del Comité de Seguridad Alimentaria Mundial (Informe 23).

Recuperado de http://www.fao.org/3/a-mu231s.pdf

FAO. (2017). América Latina y el Caribe es la región con la mayor desigualdad en la distribución de la tierra.

Recuperado de http://www.fao.org/americas/noticias/ver/es/c/879000/

FAO. (2018). Seguridad alimentaria y nutricional en América Latina y el Caribe.

Recuperado de http://www.fao.org/americas/prioridades/seguridadalimentaria/es/

Front Line Defenders. (2017). Annual Report on Human Rights Defenders at Risk in 2017. Recuperado de https://www.frontlinedefenders.org/sites/default/files/ annual_report_digital.pdf

Gobierno de Chile. (2018). Informe de Diagnóstico e Implementación de la Agenda 2030 y los Objetivos de Desarrollo Sostenible en Chile. Recuperado de https://www. undp.org/content/dam/chile/docs/ods/undp_cl_ODS_Informe_ODS_ Chile_ante_NU_Septiembre2017.pdf

González, J. (2018). Latinoamérica: una región letal para los defensores de Derechos Humanos. Recuperado de https://latinamericanpost.com/ es/23112-latinoamerica-una-region-letal-para-los-defensores-de-derechoshumanos

INDEPAZ, IEPRI, CINEP/PPP Y CCJ. (2017). Panorama de violaciones al derecho a la vida, libertad e integridad de líderes sociales. Bogotá: Impresol.

Kellogg. (2019). Desayunos para Mejores Días® busca ayudar a quienes más lo necesitan. Recuperado de https://www.hablandoconkelloggs.com/es_MX/ content/ayudando/desayuno-dias-mejores.html

Marín-Aranguren, E. M., y Trejos-Mateus, F. D. (2018). Intenciones, realizaciones y deudas con la sociedad civil. Seguimiento y análisis de políticas públicas en Colombia, 27-49.

Meléndez, J. (2018). Feminicidios, la plaga que azota a Latinoamérica. Recuperado de: http://www.eluniversal.com.mx/mundo/feminicidios-la-plaga-que-azotalatinoamerica 
ONU. (2004). Los Defensores de los Derechos Humanos: Protección del Derecho a Defender los Derechos Humanos (Folleto informativo 29). Recuperado de https://www.ohchr.org/Documents/Publications/FactSheet29sp.pdf

ONU. (2018a). Base de datos de los órganos de tratados de las Naciones Unidas. Recuperado de https://tbinternet.ohchr.org/_layouts/TreatyBodyExternal/ Treaty.aspx?CountryID $=44 \&$ Lang $=\mathrm{SP}$

ONU. (2018b). ONU Mujeres. Informe Anual 2017-2018.

Recuperado de http://annualreport.unwomen.org/es/2018

OXFAM. (2016). Un multimillonario en América Latina gana 1.154 veces lo que una persona pobre. Recuperado de https://www.oxfam.org/es/notas-prensa/un-multimillonario-en-americalatina-gana-1154-veces-lo-que-una-persona-pobre

Oxfam: "El 10\% más rico de Latinoamérica concentra el 68\% de riqueza" (2018, 22 de enero). DW. Recuperado de https://www.dw.com/es/oxfamel-10-m\%C3\%A1s-rico-de-latinoam\%C3\%A9rica-concentra-el-68-deriqueza/a-42260023

Paffenholz, T., \& Spurk, C. (2006). Civil Society, Civic Engagement, and Peacebuilding. Social Development Papers, 36.

Súbela Radio (2019). Conoce Data Igualdad, la plataforma que te pone en perspectiva de la igualdad en América Latina. Recuperado de: https://www. subela.cl/news/2019/12/3/conoce-data-igualdad-la-plataforma-que-te-poneen-perspectiva-la-desigualdad-en-amrica-latina

UNICEF. (2017). "Yo opino, es mi derecho": Llevó la voz de los niños y niñas chilenos a la Asamblea General de Naciones Unidas. Recuperado de https:// unicef.cl/web/yo-opino-es-mi-derecho-llevo-la-voz-de-los-ninos-y-ninaschilenos-a-la-asamblea-general-de-naciones-unidas/ 